\title{
Avaliação das dificuldades de aprendizagem a partir da teoria sócio-histórica: reflexões sobre patologização e medicalização da educação
}

\author{
Alacir Villa Valle Cruces*
}

\section{Resumo}

A quantidade de crianças que apresentam dificuldades de aprendizagem, principalmente nas escolas públicas, chama a atenção de profissionais e vem sendo discutida pela Psicologia Escolar e Educacional. Nosso objetivo é refletir sobre possibilidades de avaliação e intervenção a alunos que apresentam dificuldades escolares a fim de rever posições patologizantes e medicalizantes. Consideramos, em acordo com Vigotski, que apenas nos tornamos humanos a partir da interação contínua com outros indivíduos, por meio dos quais apreendemos conhecimentos acumulados histórica e culturalmente, que, ao serem elaborados e internalizados possibilitam o surgimento do pensamento científico e de todas as demais funções tipicamente humanas. Levando-se em conta que toda e qualquer educação é social e que a mediação produzida na situação de avaliação pode produzir aprendizagem, se bem planejada e organizada, é fundamental que nas avaliações das dificuldades de crianças possamos acompanhar todas as estratégias utilizadas nos jogos e nas atividades propostas, seus erros e as dificuldades apresentadas no enfrentamento dos desafios que aparecem, suas reações a esses desafios e a disponibilidade ou não para rever as estratégias, como ela se avalia diante do sucesso ou do fracasso, a fim de levantar hipóteses, propor novos desafios e pensar em modos de fazer avançar. Compreender as dificuldades que surgem depende, portanto, de uma análise qualitativa, o que contrasta com

* Dra. pelo Programa de Psicologia Escolar e do Desenvolvimento Humano, do Instituto de Psicologia da Universidade de São Paulo. Profa. do Programa de Pós-Graduação em Psicologia Educacional na UNIFIEO, profa. e supervisora de estágios no Curso de Psicologia da UMESP. alacir.cruces@metodista.br 
a atitude psicométrica, que se preocupa com o resultado da prova, realizada em condições padronizadas, e vem provocando a patologização e a medicalização da educação e da vida. Problemas de cunho escolar, político, econômico e social são transformados em patologias dos indivíduos, confirmadas por psicólogos que apontam os limites das pessoas e não suas potencialidades. A formação dos educadores e dos psicólogos deve ampliar-lhes os horizontes, fazê-los questionar concepções pseudocientíficas e preconceituosas, que se colocam como saberes éticos e de respeito à diversidade, a fim de que se possa contribuir para o desenvolvimento saudável e para a qualidade de vida das pessoas. Retomar as possibilidades de construção democrática e do potencial de desenvolvimento que a escola tem é de extrema necessidade, ainda mais num momento em que ela tem sido constantemente degradada, em que se tenta, por todos os meios, destruir sua grandeza e sua força na construção de um país melhor. Investir, com toda a comunidade escolar, em interações saudáveis e de respeito à vida, de responsabilidade e de compromisso com a garantia dos direitos e de uma ética inclusiva, não pode envolver a produção de "laudos" que rotulem crianças e jovens, retirandolhes o direito à educação integral e incapacitando-os para uma vida digna.

Palavras-chave: Avaliação Psicológica. Dificuldade de Aprendizagem. Medicalização. Teoria Sócio-Histórica.

\section{Evaluation of Learning Difficulties from Sociohis- torical Theory: Reflections on Pathologization and Medicalization of Education}

\section{Abstract}

The number of children with learning disabilities, especially in public schools, draw the attention of professionals and has been discussed by School and Educational Psychology. Our goal is to reflect on possibilities of assessment and intervention for students who have difficulties in school in order to review pathologizing and medicalizing positions. We consider, according to Vigotski, that we only become human through continuous interaction with other individuals, through which we learn historically and culturally accumulated knowledge, which, when elaborated and internalized, make possible the emergence of scientific thought and all the others typically human functions. Considering that any education is social and that the mediation produced in the assessment situation can produce learning, if well planned and organized, it is essential that in assessing chil- 
dren's difficulties we can follow all the strategies used in games and other proposed activities, their mistakes and the difficulties presented in facing the challenges that arise, their reactions to these challenges and the willingness or not to review the strategies, as it evaluates itself in the face of success or failure, in order to raise hypotheses, to propose new challenges and think of ways to move forward. Understanding the difficulties that arise depends, therefore, on a qualitative analysis, which contrasts with the psychometric attitude, which is concerned with the result of the test, performed under standardized conditions, and has led to the pathologization and medicalization of education and life. School, political, economic and social problems are transformed into pathologies of individuals, confirmed by psychologists who point out the limits of people and not their potentialities. The education of educators and psychologists must broaden their horizons, make them question pseudoscientific and prejudiced conceptions, which stand as ethical knowledge and respect for diversity, so that they can contribute to healthy development and quality people's lives. Resuming the possibilities of democratic construction and the potential for development that the school has is of utmost necessity, especially at a time when it has been constantly degraded, in which it tries, by all means, to destroy its greatness and its strength in the construction from a better country. Investing, together with the whole school community, in healthy and respectful life interactions, responsibility and commitment to guaranteeing rights and an inclusive ethic, cannot involve the production of "reports" that label children and young people, denying them the right to comprehensive education and disabling them to a dignified life.

Keywords: Psychological Evaluation. Learning disability. Medicalization. Sociohistorical Theory.

\section{Evaluación de Las Dificultades de Aprendizaje de la Teoría Sociohistórica: Reflexiones sobre la Pato- logización y la Medicación de la Educación}

\section{Resumen}

El número de niños con discapacidades de aprendizaje, especialmente en las escuelas públicas, atrae la atención de los profesionales y ha sido discutido por la psicología escolar y educativa. Nuestro objetivo es reflexionar sobre las posibilidades de evaluación e intervención para los estudiantes que tienen dificultades para revisar las posiciones de patologización y medicalización. Consideramos, según Vigotski, que solo nos convertimos en 
humanos a través de la interacción continua con otros individuos, a través de los cuales aprendemos conocimientos acumulados histórica y culturalmente, que, cuando se elaboran e internalizan, permiten el surgimiento del pensamiento científico y todos las demás funciones típicamente humanas. Considerando que cualquier educación es social y que la mediación producida en la situación de evaluación puede producir aprendizaje, si está bien planificada y organizada, es esencial que al evaluar las dificultades de los niños podamos seguir todas las estrategias utilizadas en los juegos y en las demas actividades propuestas, sus errores y las dificultades presentadas para enfrentar los desafíos que surgen, sus reacciones a estos desafíos y la voluntad o no de revisar las estrategias, ya que se evalúa a sí mismo frente al éxito o al fracaso, para plantear hipótesis, proponer nuevos desafíos y pensar en formas de avanzar. La comprensión de las dificultades que surgen depende, por lo tanto, de un análisis cualitativo, que contrasta con la actitud psicométrica, que se refiere al resultado de la prueba, realizada en condiciones estandarizadas, y ha llevado a la patologización y medicalización de la educación y la vida. Los problemas escolares, políticos, económicos y sociales se transforman en patologías de individuos, confirmadas por psicólogos que señalan los límites de las personas y no sus potencialidades. La educación de educadores y psicólogos debe ampliar sus horizontes, hacerlos cuestionar las concepciones pseudocientíficas y prejuiciosas, que se erigen como conocimiento ético y respeto por la diversidad, para que puedan contribuir a un desarrollo saludable y de calidad a la vida de las personas. Reanudar las posibilidades de construcción democrática y el potencial de desarrollo de la escuela es de suma necesidad, especialmente en un momento en que se ha degradado constantemente, intentando por todos los medios destruir su grandeza y fortaleza en su construcción de un país mejor. Invertir, junto con toda la comunidad escolar, en interacciones de vida sana y respetuosa, responsabilidad y compromiso para garantizar los derechos y una ética inclusiva, no puede implicar la producción de “informes" que etiqueten a los niños y jóvenes, quitándolos o derecho a una educación integral y les impide una vida digna.

Palabras clave: Evaluación psicológica. Discapacidad de aprendizaje. Medicalización. Teoría Sociohistórica.

\section{Introdução}

Os altos índices de repetência, evasão escolar e de crianças que apresentam dificuldades de aprendizagem, principalmente nas escolas públicas de todo o país, chamam a atenção de educadores, 
psicólogos e demais envolvidos com a área, constituindo um corpo de pesquisas e estudos denominado de "fracasso escolar". Os estudos e as discussões sobre esse tema vêm ocupando grande espaço na Psicologia Escolar e Educacional no Brasil, desde o século passado (PATTO, 1990; MOYSÉS E COLLARES, 1992; SOUZA, 1996; 1997; KALMUS E PAPARELLI, 1997; MACHADO, 1997; 2000, PROENÇA, 2002).

A partir desses estudos, movimentos para a democratização do ensino e para a garantia do direito de escolarização para toda a população se multiplicaram, apoiados no projeto cidadão da Constituição vigente.

Apesar de mudanças nas políticas educacionais na tentativa de alterar esse estado de coisas (ver, por exemplo, Resolução CEE 09/97, que institui, no Sistema de Ensino do Estado de São Paulo, o Regime de Progressão Continuada; a Resolução $\mathrm{CNE} / \mathrm{CEB} n^{\circ} 7$, de 14 de dezembro de 2010, que fixa Diretrizes Curriculares Nacionais para o ensino fundamental de nove anos e revoga a Resolução $\mathrm{CNE} / \mathrm{CEB}$ n$^{\circ}$ 2, de 07 de abril de 1998; a Resolução no 4, de 02 de outubro de 2009, que institui Diretrizes Operacionais para o Atendimento Educacional Especializado na Educação Básica; entre outras), resultados de pesquisas, divulgados recentemente, revelam que ainda estamos muito distantes de atingirmos objetivos esperados.

Dados obtidos no Censo do IBGE, em 2017, revelam que 7,0 \% dos jovens com 15 anosde idade ou mais são analfabetos, e $7,4 \%$ dos que têm 18 anos de idade ou mais também o são. Esses índices atingem 8,5\% das pessoas que têm 25 anos de idade ou mais, $11,9 \%$ das que têm 40 anos ou mais e 19,3\% das que têm 60 anos ou mais (BRASIL, 2017). Chama ainda mais a atenção o fato de que no grupo de mulheres o índice de analfabetismo é ligeiramente maior do que no dos homens, enquanto no grupo de pessoas negras os índices são acentuadamente maiores do que no grupo de pessoas brancas (4,0\% contra 9,3\%).

Essa mesma pesquisa permite concluir que as metas relativas à elevação da taxa de alfabetização e a universalização do atendi- 
mento escolar para a população de 15 a 17 anos de idade não foram cumpridas. São mais de 25 milhões de jovens de 15 a 29 anos de idade que não concluíram a graduação e não frequentam a escola, tampouco cursos pré-vestibulares ou técnicos. O grupo é majoritariamente composto por pessoas da cor preta ou parda $(64,2 \%)$ e por homens $(52,5 \%)$. Os principais motivos citados para a interrupção dos estudos são o trabalho (39,7\%), a falta de interesse $(20,1 \%)$ e a necessidade de cuidar de pessoas ou dos afazeres domésticos $(11,9 \%)$.

Além disso, chega a $27 \%$ o índice de analfabetos funcionais, conceito que engloba pessoas que cursaram a escola em algum nível, mas que mesmo assim são incapazes de compreender e interpretar textos simples e fazer operações matemáticas de baixa complexidade. Esses dados apenas confirmam que há, em nossa sociedade, uma crença, forjada durante séculos e apoiada em teorias pseudocientíficas, extremamente bem descritas e analisadas por Patto (1984; 1990), que indivíduos negros ou pardos, de classes menos favorecidas e moradores de comunidades periféricas são incapazes de aprender, profecia essa que vem se autorrealizando até os dias atuais (ROSENTHAL; JACOBSON, 1989)

Outra meta do Pano Nacional de Educação (PNE - Brasil, 2014) que não foi alcançada é a de garantir que $85 \%$ dos estudantes do Ensino Médio estejam frequentando a série esperada para a idade. Em 2017, apenas 68,4\% dos alunos que tinham entre 15 e 17 anos de idade, faixa etária que é idealmente prevista para quem cursa a última etapa da educação básica, a tinham concluído. Desmotivação e desconexão com os colegas de turma são os grandes problemas do atraso escolar, além da dificuldade para acompanhar o conteúdo ensinado, uma fragilidade que geralmente vem do ensino fundamental. Essa fragilidade, no Estado de São Paulo, tem sido atribuída, em certa medida, à Resolução CEE 09/97 (CRUCES, 2016).

Considerando a importância da escolarização de qualidade para o desenvolvimento e para a humanização das pessoas, parece necessário contribuir para a garantia desse direito, por meio de uma 
psicologia que faça a crítica às condições de ensino e de aprendizagem vigentes, às políticas públicas e às condições econômicas e sociais da população, deixando de focar-se apenas nas condições psíquicas dos alunos, o que vem sendo muito frequente, quando encaminhados a serviços de saúde.

Estudo recente, de Zibetti, Souza e Queirós (2010), após levantamento em escolas públicas da rede estadual de Rondônia, com o objetivo de compreender a produção, os atendimentos e encaminhamentos à queixa escolar de crianças em processo de alfabetização, concluiu que:

\begin{abstract}
"[...] a crença de que os problemas de aprendizagem são de ordem individual e que sua superação depende da intervenção médica ou psicológica está tão arraigada que impede que se percebam outras possibilidades de intervenção [...] o serviço de Psicologia acaba ratificando esse tipo de atuação [...] evidenciando que as novas concepções [...] ainda não chegaram à realidade" (p. 504).
\end{abstract}

Diante dessas constatações, este artigo tem como objetivo refletir sobre novas possibilidades de avaliação e intervenção junto a alunos que apresentam dificuldades escolares, a fim de contribuir para a superação das mesmas e para a desconstrução das visões patologizantes e medicalizantes tão frequentes em nossas escolas atualmente. Segundo nossa perspectiva, essa transformação é necessária para que as profecias de educadores e demais profissionais da saúde não se tornem profecias autorrealizadoras e para que os dados estatísticos de anos vindouros apresentem resultados diferentes dos já apresentados.

A fim de sustentar a proposta que será apresentada, utilizaremos os conceitos desenvolvidos por Vigotski e seus colaboradores, que serão retomados na primeira parte deste trabalho. $\mathrm{Na}$ segunda serão apresentadas as críticas ao modelo de avaliação psicológica tradicional, com a concomitante construção de outro modelo de avaliação que, com base na perspectiva sócio-histórica, promova avanços nas aprendizagens e no desenvolvimento integral e contribua para a 
quebra de paradigmas medicalizantes e patologizantes, encaminhando-nos para a apresentação de nossas considerações finais.

\section{Aprendizagem e desenvolvimento na Psicologia Sócio-Histórica}

Têm sido amplamente discutidas as proposições teóricas de Vygotsky (1989; 2004) e seus colaboradores (VIGOTSKI; LURIA; LEONTIEV, 1988), que são encontradas em farta literatura e, portanto, não serão aqui retomadas. No entanto, alguns princípios que eles defendem, no que se refere ao desenvolvimento humano, precisam ser retomados para que possamos, a partir deles, construir uma proposta de trabalho frente às dificuldades de aprendizagem.

Eles consideram, diferentemente de todos os demais teóricos da Psicologia e da Educação, que os indivíduos não nascem humanos, mas se tornam humanos a partir da interação contínua com os demais indivíduos, que lhes transmitem conhecimentos acumulados histórica e culturalmente, captados e processados por intermédio de seu aparato biológico. Esse processo de humanização é lento e contínuo, se dá por meio das aprendizagens cotidianas e práticas, que, ao serem elaboradas e internalizadas possibilitam transformações qualitativas nas funções psicológicas. Essas funções se sofisticam, se tornam mais complexas, possibilitando o surgimento do pensamento científico e abstrato, da atenção concentrada, da capacidade de planejar, analisar e organizar ações, do equilíbrio das emoções e de todas as demais funções tipicamente humanas (VIGOTSKI, 2012; 1998).

Deve-se, ainda, considerar que o desenvolvimento integral das potencialidades individuais, segundo Vigotski e seus colaboradores, só ocorre em um meio social e com a mediação de outros indivíduos. A mediação é a incorporação de instrumentos técnicos e simbólicos na estrutura da atividade humana, produzindo significações e viabilizando a regulação da conduta. $\mathrm{O}$ homem significa a si próprio e ao mundo por meio das experiências sociais e não de modo direto. Isso significa dizer que não há limites predetermina- 
dos do que ele irá atingir e que as metas a serem atingidas não podem ser subestimadas. Em função disso, propõem outras diretrizes para a educação, sempre numa visão prospectiva e que considere o desenvolvimento humano em sua dinâmica, privilegiando os potenciais e os talentos.

O terceiro aspecto a ser considerado, que decorre dos anteriores, diz respeito à importância das aprendizagens e da escolarização para o desenvolvimento humano. Por meio das interações sociais, internalizamos a cultura em que estamos inseridos, a partir da internalização dos conhecimentos previamente organizados e sistematizados, por um mediador qualificado, e podem ocorrer transformações dos conhecimentos cotidianos em científicos, que propiciarão o desenvolvimento das funções psicológicas superiores e a humanização.

Tendo como fundamento o materialismo histórico dialético, Vigotski considera, ainda, que a aprendizagem possível está relacionada ao nível de desenvolvimento alcançado, sendo assim, adquire relevo especial a análise do processo de comunicação e a análise do modo como a pessoa constrói os conceitos comunicados e, portanto, a análise qualitativa das "estratégias" utilizadas, dos erros, do processo de generalização. Trata-se de compreender como funcionam esses mecanismos mentais que permitem a construção dos conceitos e como se modificam em função do desenvolvimento.

Isto contrasta claramente com a atitude psicométrica, que se preocupa apenas com o resultado da prova apresentada em condições padronizadas e, portanto, prescinde, quase totalmente, do processo de construção da própria solução, baseando-se no princípio segundo o qual o resultado final representa todo o processo de solução. Mas, como os processos de solução variam de forma radical, justamente em função do desenvolvimento, deduz-se que os psicometristas não têm em conta uma das variáveis fundamentais da aprendizagem: o desenvolvimento. Isso determina uma consequência especialmente interessante, os resultados obtidos com a aplicação dos testes de inteligência, em todo o período da infância, 
não se mantêm estáveis ao longo dela, contradizendo os próprios pressupostos dos testes (CECCHINI, 2005).

Ainda assim, sabemos que essas são as práticas frequentemente utilizadas por psicólogos na avaliação das dificuldades de aprendizagem.

\section{Críticas à avaliação psicológica tradicional e pro- posta de um novo modelo de trabalho}

Pode-se constatar que grande parte dos atendimentos às queixas escolares de crianças e jovens ainda é feita por meio de psicodiagnóstico tradicional, em que são avaliadas as capacidades intelectuais e afetivo-emocionais (SOUZA, 1996; MACHADO, 1997, 2000; CRUZ, 1994; CABRAL; SAWAIA, 2001; COLLARES; MOYSÉS, 1986), centrando-se, portanto, no aluno e em sua família. As indicações que dele decorrem envolvem, geralmente, a realização de psicoterapia e de orientação aos pais, confirmandose e reiterando-se, dessa maneira, que o problema é do aluno, que a dificuldade de aprender está fundada em seu aparato orgânico e é herdada de seus familiares. Nem a escola, como instituição, nem as políticas públicas que as regem, nem o modo como essa política é colocada em prática pelos seus atores precisam ser investigadas sob essa concepção, apenas o aluno. Como afirmam Marçal e Silva (2006), deve-se questionar a formação de profissionais, que falham ao desconsiderar as influências do contexto escolar e as relações de ensino e aprendizagem, atribuindo à queixa caráter essencialmente psicológico.

Esse tipo de trabalho que vem sendo realizado, além de se mostrar pouco eficaz para o desenvolvimento dos alunos e para a superação de seus entraves, vem provocando a patologização e a medicalização da educação e da vida. Dados expostos no site do Fórum sobre a medicalização da educação e da sociedade (http:// medicalizacao.org.br) revelam a preocupação com o aumento constante de diagnósticos, com a medicalização e a patologização dos comportamentos:

"Entendemos por medicalização o processo em que as questões da vida 
social, sempre complexas, multifatoriais e marcadas pela cultura e pelo tempo histórico, são reduzidas à lógica médica, vinculando aquilo que não está adequado às normas sociais a uma suposta causalidade orgânica, expressa no adoecimento do indivíduo".

Estudos vêm reforçando o conceito de medicalização (CARDOSO; HASHIZUME, 2018) ao demonstrar que problemas de cunho escolar, político, econômico e social são transformados em patologias dos indivíduos e violam os direitos à vida e à segurança pessoal. Um dos mais consistentes vem sendo desenvolvido há anos por Moysés e Collares (MOYSÉS E COLLARES, 1992; 2010; 2013, COLLARES E MOYSÉS, 1996; 2010, MOYSÉS, 2001; 2010). Moysés (2010) questiona se a dislexia existe, tomando como base o fato de que ela é definida como um transtorno neurológico, sem que se possa encontrar qualquer problema neurológico nas pessoas diagnosticadas como disléxicas. Ela aponta, ainda, a falha no método utilizado para esse diagnóstico, que se realiza apenas com testes escritos, o que evidencia apenas aquilo que já tinha sido verificado: a dificuldade de compreender e de utilizar o sistema de escrita! Dentro desse mesmo raciocínio, Moysés e Collares (1992), Collares e Moysés (1996) e Moysés (2001) explicam a construção de doenças que confirmam preconceitos e evidenciam mecanismos ideológicos que encobrem fenômenos políticos, sociais e econômicos.

Atividades profissionais de psicólogos, que poderiam contribuir para que entraves no processo de desenvolvimento do conhecimento fossem superados, por meio do trabalho em equipe e na direção da promoção da saúde têm, ao contrário, produzido "laudos" que excluem e estigmatizam crianças e jovens, diminuindo significativamente suas possibilidades de superarem suas dificuldades ao estabelecerem, com um diagnóstico, os limites dessas pessoas e não as suas potencialidades.

Ainda que se defenda, na maioria das situações, a inclusão e a permanência dessas pessoas nos bancos escolares, o rótulo por meio do qual elas passam a ser conhecidas, traz, para o imaginário escolar, apenas seus limites, limites com os quais os educadores e 
familiares acreditam que não podem e não estão preparados para lidar e, muito menos, ultrapassar. Nesse sentido, a avaliação que deveria nos levar a conhecer e compreender as dificuldades a serem enfrentadas para que essa pessoa se desenvolva integralmente, determina quem ela será, como se comportará e que características terá para toda sua vida.

Cecchini (2005, p. 9) considera que os estudos sobre o desenvolvimento cognitivo revelam claramente que as " potencialidades' intelectuais de um 'estudante' que aprende são, em geral, muito superiores às que supõe quem elabora os programas; em contrapartida, as motivações para aprender são normalmente mais escassas do que o previsto. E isto não por 'má vontade', mas sim, na maioria dos casos, por deficiências estruturais dos programas ou porque os próprios programas não resultam interessantes para aqueles que os deveriam aprender".

Considerando o suporte teórico que a Psicologia Sócio Histórica traz, o trabalho a ser realizado, diante das dificuldades de aprendizagem, não pode se centrar apenas no indivíduo. Ele deve assumir uma dimensão social e institucional, levando-se em conta que toda e qualquer educação é social, que toda aprendizagem se produz na interação com a cultura e com o apoio de mediadores (VIGOTSKI, 2004; PINO, 2013).

O desenvolvimento humano é um processo, que depende de aprendizagens, e está em constante transformação. Não acreditamos, portanto, que possamos avaliá-lo com instrumentos padronizados, que apenas quantifiquem habilidades já desenvolvidas. Se pensamos em conhecer potencialidades precisamos partir delas, conhecê-las em todas as suas formas e aplicações, a fim de chegar naquelas que ainda precisam ser desenvolvidas com o auxílio de mediadores. E isso só será possível em um clima amistoso e cooperativo, com propostas motivadoras e agradáveis e não com provas e testes que inibam, desencorajem e afastem as crianças e jovens de seus interesses e de suas possibilidades. 
Interação e aprendizagens sempre provocam transformações, segundo a Psicologia Sócio Histórica. Sendo assim, toda avaliação, como forma de interação, provoca alterações qualitativas, que dependem das possibilidades comunicativas e compreensivas dos envolvidos e são intervenções sobre o processo avaliado. A mediação produzida na situação de avaliação, por si só, produz aprendizagem, se bem planejada e organizada. Torna-se fundamental, portanto, acompanharmos todas as estratégias utilizadas nos jogos e nas atividades propostas, os erros e as dificuldades apresentadas no enfrentamento dos desafios que aparecem, as reações a esses desafios e a disponibilidade ou não para rever as estratégias, como e se aceita ajuda para resolvê-los, se consegue generalizar conquistas para enfrentar outros desafios, como se avalia diante de seu sucesso ou do seu fracasso, enfim, acompanhar e observar tudo que acontece e como acontece a fim de levantar hipóteses, propor novos desafios e pensar em modos de fazer avançar. Trata-se de compreender como funcionam esses mecanismos mentais que permitem a construção dos conceitos e o desenvolvimento de novos potenciais.

Levando em conta essas questões devemos ter em mente que a avaliação deve ser detalhada, dinâmica e flexível, baseada na aplicação de provas diversas, sempre lúdicas e prazerosas, dirigidas aos diversos aspectos do comportamento, em "um esforço clinicamente criativo que requer pensamento crítico, com atenção particular não só ao conteúdo das respostas produzidas pelo paciente, mas para a forma como são expressas" (FACCI; EIDT; TULESKI, 2006, p. 108).

Se partirmos do pressuposto de que as funções psicológicas superiores só se desenvolvem em sua forma absoluta a partir de mediações culturais, o foco do problema nas dificuldades de aprendizagem desloca-se do nível individual para o social e passa a ser inevitável a discussão sobre a qualidade da mediação produzida.

Deve-se priorizar a análise explicativa e não descritiva, voltando ao ponto de partida e restabelecendo todos os processos de desenvolvimento a fim de acompanhá-los em sua gênese, mas sem- 
pre os estudando como processos e não em sua condição estática e momentânea ou fossilizada (VYGOTSKY, 1989).

Ao centrar nossa avaliação no aluno que apresenta dificuldades, patologizamos seus comportamentos e seus modos de lidar com as questões do dia a dia, sem mostrar-lhe novas possibilidades, ainda desconhecidas para ele, mas já construídas em nossa sociedade. Quando essa avaliação se faz por meio de testes psicológicos padronizados, apenas consideramos suas respostas, seus erros e seus acertos, mas não como raciocinou diante da tarefa que lhe foi proposta. Suas dificuldades evidenciam-se, sem que suas possibilidades tenham possibilidade de aparecer.

A teoria sócio-histórica, que se fundamenta no processo dialético de construção contínua do conhecimento, em oposição à avaliação tradicional, cuidará de descobrir aqueles conhecimentos que se encontram na zona de desenvolvimento proximal, a fim de nela trabalhar e provocar o desenvolvimento das funções que ainda precisam de mediação. A concepção de que as possibilidades de desenvolvimento estão em embrião, em um cérebro plástico e flexível e poderão ser desenvolvidas, reforça a ideia de que devemos compreender o funcionamento da pessoa em avaliação, a fim de mediar a construção de novas ações e de novos modos de enfrentar a realidade.

Bastos e Alves (2013) explicam que, além da anatomia e neurofisiologia do cérebro, da localização e função de determinadas áreas, sofremos influências de estímulos do mundo exterior e das relações sociais, o que implica que há aprendizado e desenvolvimento cognitivo ao longo de toda a nossa vida. Nesta perspectiva anatômica e funcional do substrato neural das funções mentais superiores, deve-se levar em conta a maturação destas estruturas, pois a aprendizagem e a cognição inerentes a estas funções dependem do desenvolvimento. Essa concepção dinâmica admite estar a consciência semântica estruturada não em partes anatômicas localizáveis, mas em sistemas neurais funcionalmente estabelecidos ao longo da vida de um indivíduo. Essa funcionalidade ou dinamismo cerebral vai ao encontro da descrição de Luria (2006), em relação 
à base cerebral da atividade consciente humana constituída por sistemas funcionais complexos e diferenciados. Vigotski também defende um modelo dinâmico, em que as áreas cerebrais (auditiva, sensorial e tátil-cinestésica, visual, planejamento consciente do comportamento e programas de ação) se integram funcionalmente, são influenciadas pelo meio sociocultural e são cognitivamente importantes para a aprendizagem numa relação intrínseca com a linguagem, mediando nossas funções psicointelectuais.

Com a maturação das estruturas e sistemas encefálicos, a aprendizagem propicia o desenvolvimento cognitivo e, assim como as funções mentais superiores, a linguagem progride para a reversibilidade abstrata e generalizada do pensamento, num trânsito em rede, com diversas ramificações e sem direções fixas ou determinadas. Desse modo, podemos concluir que o aprendizado provoca ou promove o desenvolvimento cognitivo por meio da proliferação de redes neuronais e transmissão sináptica no sistema nervoso central, pois "quanto mais aprendemos, mais redes formamos e mais neurônios teremos para propiciar plasticidade cerebral" (FERREIRA, 2009, p.56-57).

De forma similar, essas definições sobre plasticidade cerebral já eram reconhecidas por Vygotsky (2006) e Luria (2010) quando se referiam, respectivamente, à maturação do sistema nervoso central e aprendizagem, em acordo com o conceito de Zona de Desenvolvimento Proximal e à reorganização funcional dos sistemas funcionais do cérebro. $\mathrm{O}$ trabalho que acontece, a partir da mediação nesta zona e que afeta a microgênese, é concebido como dinâmico, flexível e singular a cada indivíduo, compreendendo a heterogeneidade humana e seu hibridismo linguístico. Nesta perspectiva, Ferreira (2009, p. 53) reforça a correlação entre a aprendizagem e o desenvolvimento cerebral, quando relata que cada aprendizado determina uma transformação cerebral, de forma anatômica, pois $\mathrm{o}(\mathrm{s})$ estímulo(s) leva (m) à construção de uma nova ou de novas conexões entre os dendritos de diferentes neurônios, localizados em diferentes regiões cerebrais". 


\section{Considerações finais}

Ao compreender os processos de aprendizagem e de desenvolvimento, nos deparamos com políticas públicas em educação, que, apesar de bem fundamentadas, não podem ser colocadas em prática, como propostas. Os limites são inúmeros e vão desde o fato de que um professor tem um grande número de alunos e poucos recursos para lidar com eles, até o fato de que o próprio projeto político pedagógico da escola lhe é desconhecido. Assim como o projeto político pedagógico, muitas resoluções lhe são impostas, sem que ele tenha sido ouvido, sem que tenha sequer tomado conhecimento das mesmas antes de chegar à escola.

Medidas como a Progressão Continuada, a inclusão de todos os alunos em salas e em escolas regulares, o aumento do ensino fundamental para nove anos, entre tantas outras, aconteceram, pelo menos no Estado de São Paulo, sem que houvesse a necessária discussão e sem que houvesse preparo estrutural e humano para isso, colocando à tona funcionamentos escolares que provocam o fracasso e o sofrimento, seja de alunos, de professores ou mesmo de pais (SOUZA, B., 2007), evidenciando que as dificuldades e o fracasso na e da escola têm uma história e uma condição muito mais complexa, que, além dos dados já assinalados, variam a depender das concepções e das intenções dos poderes municipais, estaduais e federais, que mudam constantemente, a depender do momento político e de quem assume o poder em cada momento, muitas vezes sem a necessária correlação e a necessária continuidade à auto-avaliação e ao aprimoramento.

Diante de dados como esses, que merecem estudo muito mais detalhado, podemos, com Patto (1990), concluir que a própria escola produz o fracasso escolar, a partir das políticas que as regem e da forma como são elas são implementadas. A análise crítica do fracasso e das queixas escolares, das dificuldades em manter os jovens nas escolas e de desenvolvê-los integralmente, de desafiá-los e de mantê-los interessados nos conteúdos que lhes são expostos e da forma como são expostos deve passar, necessariamente, para 
a formação crítica de educadores e de psicólogos, a fim de que sua formação permita que eles também se desenvolvam e sejam capazes dessa análise.

A formação dos educadores e dos psicólogos deve ampliarlhes os horizontes para além das questões clínicas e patologizantes, que quase que concomitantemente têm levado à medicalização, assumindo o compromisso com uma educação de qualidade, que busque nas estratégias pedagógicas e nas políticas educacionais modos para a superação dos entraves encontrados. É importante assinalar que, a partir do modelo médico, esses profissionais patologizam comportamentos normais, na tentativa de adequar as pessoas às normas produzidas por interesses de minorias e à ilusão do aluno ideal. É preciso, ainda, questionar concepções pseudocientíficas e preconceituosas, que se colocam como saberes éticos e de respeito à diversidade, a fim de que se possa contribuir para o desenvolvimento saudável e para a qualidade de vida das pessoas, por meio da mediação e da ajuda na compreensão cada vez mais crítica e aprofundada da realidade que nos cerca.

Nesse sentido e partindo do fato de que a Declaração Universal dos Direitos do Homem deixa claro que todas as pessoas gozam do direito à vida e à segurança pessoal, que nossa Constituição Federal garante que todos os brasileiros devem ter educação de qualidade, avaliações padronizadas levam a diagnósticos que patologizam comportamentos, que estigmatizam e excluem pessoas, o que nos parece caminhar na contramão da garantia dos direitos já adquiridos.

As avaliações das dificuldades, quando tomam como base a necessidade de compreender o desenvolvimento humano, que fazem das interações momentos de construção de conhecimento e que respeitam a diversidade e a singularidade desta construção, levam à autonomia e ao uso de conceitos cotidianos e científicos para a análise da realidade, desconstroem as dificuldades e as incapacidades, retomando a possibilidade de superação. Neste sentido, e partindo de que as capacidades são inerentes a todos, caminhamos na direção da humanização e não da patologização. Comportamentos e ações se 
desenvolvem dessa forma e não com a medicação ou com a medicalização, que apenas importam a quem deles extrai lucros.

Retomar as possibilidades de construção democrática e do potencial de desenvolvimento que a escola tem é de extrema necessidade, ainda mais num momento em que ela tem sido constantemente degradada, em que se tenta, por todos os meios, destruir sua grandeza e sua força na construção de um país melhor. Investir na construção, com toda a comunidade escolar, de interações saudáveis e de respeito à vida, de responsabilidade e de compromisso com a garantia dos direitos e de uma ética inclusiva, não pode envolver a produção de "laudos" que rotulem crianças e jovens, retirando-lhes o direito à educação integral e incapacitando-os para uma vida digna.

\section{Referências}

BASTOS, L. S.; ALVES, M. P. As influências de Vygotsky e Luria à neurociência contemporânea e à compreensão do processo de aprendizagem. Revista Práxis. Rio de Janeiro, vol. V, n 10, p. 41-53, dezembro 2013.

BRASIL. Lei no 13.005/ 2014 que dispõe sobre o Plano Nacional de Educação e dá outras providências. Brasília, DF: Presidência da República. Disponível em: http://pne.mec.gov.br/18-planos-subnacionais-de-educacao/543-plano-nacional-de-educacao-lei-n-13-005-2014. Acesso em 24set. 2019.

. IBGE. Anuário. Brasília, 2017. Disponível em: (https://agenciadenoticias.ibge.gov.br/media/com_mediaibge/arquivos/05dc6273be644304b520efd585434917.pdf)Acesso em 24 set. 2019.

BRASIL/ MINISTÉRIO DA EDUCAÇÃO/ CONSELHO NACIONAL DE EDUCAÇÃO BÁSICA/ CÂMARA DE EDUCAÇÃO BÁSICA. Resolução no 4, de 2 de outubro de 2009, Institui Diretrizes Operacionais para o Atendimento Educacional Especializado na Educação Básica, modalidade Educação Especial. Brasília: CNE/CEB, 2009.

BRASIL/ MINISTÉRIO DA EDUCAÇÃO/ CONSELHO NACIONAL DE EDUCAÇÃO BÁSICA/ CÂMARA DE EDUCAÇÃO BÁSICA. Resolução n ${ }^{\circ}$ 7, de 14 de dezembro de 2010, Fixa Diretrizes Curriculares Nacionais para o ensino fundamental de nove anos e revoga a Resolução CNE/CEB n 2 de 07 de abril de 1998. Brasília: CNE/CEB, 2009. 
CABRAL, E.; SAWAYA, S. M. Concepções e atuação profissional diante das queixas escolares: os psicólogos nos serviços públicos de saúde. Estudos de Psicologia. Natal, v. 6, n. 2, p. 143-155, 2001.

CARDOSO, D. F. M.; HASHIZUME, C. M. Medicalização na educação: refletindo sobre seus desdobramentos na saúde pública e Direitos Humanos. São Bernardo do Campo/ SP. Cadernos de Educação. São Bernardo do Campo/ SP, v.17, n. 35 , p. $55-70$, jul.-dez. 2018

CECCHINI, M. Introdução. In: LURIA, LEONTIEV, VYGOTSKY E OUTROS. Psicologia e pedagogia: bases psicológicas da aprendizagem e do desenvolvimento. São Paulo: Centauro, 2005.

COLLARES, C. A. L.; MOYSÉS, M. A. A. Educação ou saúde? Educação X Saúde? Educação e Saúde! Cadernos CEDES. São Paulo, v. 15, p. 7-16, 1986.

CRUCES, A. V. V. O regime de progressão continuada em escolas públicas de São Paulo: uma análise a partir de estágio em Psicologia Escolar. In: CAMPOS, H. R.; SOUZA, M. P. R; FACCI, M. G. D. Psicologia e políticas educacionais. Natal/ RN: EDUFRN, 2016.

CRUZ, S. H. V. O ciclo básico construído pela escola. Tese (Doutorado em Psicologia Escolar) - Instituto de Psicologia, Universidade de São Paulo, São Paulo, 1994.

FACCI, M. G.; EIDT, N. M. \& TULESKI, S. C. Contribuições da teoria histórica-cultural para o processo de avaliação psicoeducacional. Psicologia USP, São Paulo, v. 17, n. 1, p. 99-124, 2006.

FERREIRA, V. J. A. Dislexia e Outros Distúrbios da Leitura-Escrita. In: Zorzi, J.; Capellini, S. Organização Funcional do Cérebro no Processo de Aprender. $2^{\mathrm{a}}$ ed. São José dos Campos: Pulso, 2009.

KALMUS, J.; PAPARELLI, R. Para além dos juros da escola: as repercussões do fracasso escolar na vida de crianças reprovadas. In: MACHADO, A. M.; SOUZA, M. P. R. (Orgs.). Psicologia escolar: em busca de novos rumos. São Paulo: Casa do Psicólogo, 1997. p. 153-181.

MARÇAL, V. P. B.; SILVA, S. M. C. S. A queixa escolar nos ambulatórios públicos de Saúde Mental: Práticas e Concepções. Revista Semestral da Associação Brasileira de Psicologia Escolar e Educacional, Maringá, v. 10, n. 1, p. 121-131, 2006. 
MACHADO, A. M. Relato de uma intervenção na Escola Pública. In: MACHADO, A. M.; SOUZA, M. P. R. (Orgs.). Psicologia escolar: em busca de novos rumos. São Paulo: Casa do Psicólogo, 1997.p. 87-100.

MACHADO, A. M. Avaliação Psicológica na Educação: Mudanças Necessárias In: TANAMACHI, E.; PROENÇA, M.; ROCHA, M. Psicologia e Educação: desafios teórico-práticos. São Paulo: Casa do Psicólogo, 2000, p. 143-147.

MEIRA, M. E. M.; ANTUNES, M. A. M. (Orgs.) Psicologia escolar: Teorias Críticas. São Paulo: Casa do Psicólogo, 2003.

MEIRA, M. E. M.; ANTUNES, M. A. M. (Orgs.) Psicologia escolar: Práticas Críticas. São Paulo: Casa do Psicólogo, 2003.

MOYSÉS, M. A. A.; COLLARES, C. A. A história não contada dos distúrbios de aprendizagem. Cadernos CEDES, São Paulo, v. 28, p. 31-48, 1992.

PATTO, M. H. S. Psicologia e ideologia. São Paulo: T. A. Queiroz, 1984.

PATTO, M.H.S. A Produção do Fracasso Escolar: Histórias de Submissão e Rebeldia. São Paulo: T. A. Queiroz, 1990.

PINO, A. Natureza e cultura: as funções naturais na constituição cultural do homem. In: SMOLKA, A. L. B.; NOGUEIRA, A. L. (Orgs.) Estudos na perspectiva de Vigotski - gênese e emergência das funções psicológicas. p. 71-98. Campinas, SP: Mercado das Letras, 2013.

PROENÇA, M. Problemas de Aprendizagem ou Problemas de Escolarização? Repensando o Cotidiano Escolar à Luz da Perspectiva Histórico-Crítica em Psicologia In: Psicologia, educação e as temáticas da vida contemporânea. São Paulo: Moderna, 2002.p. 177-195.

ROSENTHAL, R; JACOBSON, L. Profecias auto-realizadoras em sala de aula: as expectativas de professores como determinantes não intencionais da competência intelectual. In: PATTO, M. H. S. Introdução à Psicologia Escolar. São Paulo: T. A. Queiroz, 1989.p. 258-295.

SÃO PAULO/ SECRETARIA ESTADUAL DE EDUCAÇÃO/ CONSELHO ESTADUAL DE EDUCAÇÃO. Deliberação CEE 09/97, que Institui, no Sistema de Ensino do Estado de São Paulo o Regime de Progressão Continuada, 1997. 
SOUZA, B. P. Funcionamentos escolares e produção de fracasso escolar sofrimento. In: SOUZA, B. P. (Org.) Orientação à queixa escolar. São Paulo: Casa do Psicólogo, 2007. p. 241-278.

SOUZA, M. P. R.A queixa escolar e a formação do psicólogo. Tese (Doutorado em Psicologia Escolar) - Instituto de Psicologia, Universidade de São Paulo, São Paulo, 1996.

SOUZA, M. P. R. A queixa escolar e o predomínio de uma visão de mundo. In: MACHADO, A. M.; SOUZA, M. P. R. (Orgs.). Psicologia escolar: em busca de novos rumos. São Paulo: Casa do Psicólogo, 1997. p. 17-34.

VYGOTSKY, L. S. A formação social da mente. São Paulo: Martins Fontes, 1989.

VIGOTSKI, L. S. O desenvolvimento psicológico na infância. São Paulo: Martins Fontes, 1998.

VIGOTSKI, L. S. Psicologia pedagógica. São Paulo: Martins Fontes, 2004.

VYGOTSKI, L. S. Obras escogidas - III - Problemas Del desarrollo de La psique. Espanha, Madrid: Machado Grupo de distribución, 2012.

VIGOTSKII, L. S.; LURIA, A. R.; LEONTIEV, A. N. Linguagem, desenvolvimento e aprendizagem. São Paulo: Ícone, 1988.

ZIBETTI, M. L. T.; SOUZA, F. L. F.; QUEIRÓS, K. J. M. Quando a escola recorre à psicologia: mecanismos de produção, encaminhamento e atendimento à queixa na alfabetização. Estudos e pesquisas em Psicologia, Rio de Janeiro, v. 10, n. 2, p. 490-506, 2010.

Submetido em: 12-11-2019

Aceito em: 26-11-2019 